\title{
Recombinant lentivirus with enhanced expression of caudal-related homeobox protein 2 inhibits human colorectal cancer cell proliferation in vitro
}

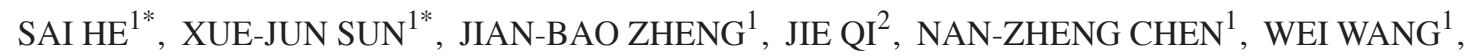 \\ GUANG-BING WEI ${ }^{1}$, DONG LIU ${ }^{1}$, JUN-HUI YU ${ }^{1}$, SHAO-YING LU ${ }^{1}$ and HUI WANG ${ }^{3}$ \\ ${ }^{1}$ Department of General Surgery, First Affiliated Hospital of Medical College, Xi'an Jiaotong University, Xi'an, \\ Shaanxi 710061; ${ }^{2}$ Second Department of Cardiovascular Medicine and ${ }^{3}$ Department of Anesthesiology, \\ Shaanxi Provincial People's Hospital, Xi'an, Shaanxi 710068, P.R. China
}

Received June 5, 2014; Accepted February 27, 2015

DOI: $10.3892 / \mathrm{mmr} .2015 .3594$

\begin{abstract}
Caudal-related homeobox protein 2 (CDX2), a tumor suppressor in the adult colon, is overexpressed under a non-cancer specific cytomegalovirus promoter in certain tumor cells; furthermore, non-specific expression of CDX2 may result in aberrant side effects in normal cells. The human telomerase reverse transcriptase (hTERT) promoter is active in the majority of cancer cells but not in normal cells. Hypoxia is a key feature of solid tumors, and targeted genes may be significantly upregulated by five copies of hypoxia-response elements (HREs) under hypoxic conditions. However, the effect of CDX2 overexpression, as controlled by five copies of HREs and the hTERT promoter, on human colorectal cancer (CRC) cell proliferation in vitro remains to be fully elucidated. In the current study, a recombinant lentivirus containing the CDX2 gene under the control of five HREs and the hTERT promoter was generated. An immunofluorescence assay was used to detect CDX 2 expression by the $5 \mathrm{HhC}$ lentivirus, whereas an MTT assay was used to detect the effects of $\mathrm{CoCl}_{2}$ on the viability of LoVo cells. Western blot analysis was conducted in order to determine the relative ratios of recombinant CDX2 protein to the internal control $\beta$-actin, following $5 \mathrm{HhC} /$
\end{abstract}

Correspondence to: Dr Jian-Bao Zheng, Department of General Surgery, First Affiliated Hospital of Medical College, Xi'an Jiaotong University, 277 West Yanta Road, Xi'an, Shaanxi 710061, P.R. China E-mail: bob.zheng@stu.xjtu.edu.cn

*Contributed equally

Abbreviations: CDX2, caudal-related homeobox protein 2; hTERT, human telomerase reverse transcriptase; HREs, hypoxia-response elements; CMV, cytomegalovirus; CRC, colorectal cancer; MTT, 3-(4,5-dimethylthiazol-2yl)-2,5-diphenyltetrazolium bromide

Key words: hypoxia response element, human telomerase catalytic subunit, caudal-related homeobox protein 2, proliferation, colon cancer
LoVo cell culture under normoxic and hypoxic conditions (100, $200,300,400$ or $500 \mu \mathrm{mol} / 1 \mathrm{CoCl}_{2}$ ) for $24 \mathrm{~h}$, then for 12,24 or $36 \mathrm{~h}$ with the optimal concentration $(300 \mu \mathrm{mol} / \mathrm{l})$ of $\mathrm{CoCl}_{2}$. Reverse transcription polymerase chain reaction analysis was used to determine the transcription of recombinant CDX2 mRNA following culture of $5 \mathrm{HhC} / \mathrm{LoVo}$ cells under normoxic or hypoxic conditions. Finally, a cloning assay was used to detect the proliferative ability of $5 \mathrm{HhC} / \mathrm{LoVo}$ and $5 \mathrm{Hh}$ cells. High CDX2 expression was observed in hTERT-positive LoVo cells under hypoxic conditions, an effect which was mimicked by treatment with $\mathrm{CoCl}_{2}$ to inhibit $\mathrm{LoVo}$ cell proliferation in vitro. High expression of CDX2 therefore provides a promising strategy for the development of novel targeted treatments and gene therapy for CRC.

\section{Introduction}

Colorectal cancer (CRC) is the third most common type of cancer worldwide, with $\sim 1.4$ million novel cases diagnosed in 2012 (1). At present, the treatment of CRC involves surgical resection, chemotherapy, radiotherapy and immunotherapy (2). However, the therapeutic efficacy, particularly for advanced CRC, is limited (3).

Caudal-related homeobox protein 2 (CDX2), an intestinal transcription factor, is critically involved in the development, proliferation and differentiation of intestinal epithelial cells (4-7). In addition, CDX2 is a tumor-suppressor gene in colorectal cancer (8-10), and reduces mobility and antagonizes dissemination of colon cancer cells in vitro and in vivo (11). By contrast, the presence of reduced CDX2 expression levels is a predictor for poor overall survival amongst patients with colorectal cancer (12). Therefore, forced overexpression of CDX2 under a cytomegalovirus (CMV) promoter in colon cancer cells is used to inhibit LoVo colon cancer cell invasion (13) and gastric cancer progression (14).

However, due to the fact that non-specific expression of CDX2 may lead to the generation of side effects, regulated colorectal cancer cell-specific expression of CDX2 is necessary. The human telomerase reverse transcriptase (hTERT) promoter is active in the majority of cancer cells but not normal 
cells $(15,16)$. Therefore, this promoter has previously been used to target A549 human lung adenocarcinoma cells (17) and human gastric cancer MKN45 cells (18).

Hypoxia is a major feature of solid tumors $(19,20)$ and induces hypoxia-inducible factor- $1 \alpha$ (HIF-1 $\alpha$ ) expression, which binds to the hypoxia-response elements (HREs) of various target genes (21) and activates their transcription in order to regulate glucose transport and angiogenesis, and potentially to enhance the survival of tumor cells $(22,23)$. Previous studies have reported that targeted genes may be significantly upregulated by five copies of HREs under hypoxic conditions $(24,25)$.

At present, the effects of CDX2 overexpression, under the control of five copies of HREs and the hTERT promoter, on human colorectal cancer cell proliferation in vitro remain unclear. In the current study it was hypothesized that CDX2 overexpression specifically inhibits human colorectal cancer cell proliferation under hypoxic conditions.

\section{Materials and methods}

Polymerase chain reaction (PCR) amplification of target $D N A$. The hTERT gene promoter and CDX2 gene were amplified from a DNA library of hTERT(+) CRC cells and pEGFP-C1-CDX2 (26), respectively, by PCR using specific primers (Table I). hTERT was obtained using the hTERT forward and reversel primer, whereas 5HRE + hTERT used the forward 5HRE primer and the hTERT reverse 2 primer. For the hTERT promoter, the PCR cycling conditions were as follows: Amplification at $98^{\circ} \mathrm{C}$ for $2 \mathrm{~min}, 30$ cycles of $98^{\circ} \mathrm{C}$ for $10 \mathrm{sec}, 55^{\circ} \mathrm{C}$ for $15 \mathrm{sec}$ and $72^{\circ} \mathrm{C}$ for $30 \mathrm{sec}$, followed by an extension step at $72^{\circ} \mathrm{C}$ for $10 \mathrm{~min}$. For the CDX2 promoter, the conditions were as follows: Amplification at $98^{\circ} \mathrm{C}$ for $2 \mathrm{~min}$, 35 cycles of $98^{\circ} \mathrm{C}$ for $20 \mathrm{sec}, 59^{\circ} \mathrm{C}$ for $30 \mathrm{sec}$ and $72^{\circ} \mathrm{C}$ for $1 \mathrm{~min}$, followed by an extension step at $72^{\circ} \mathrm{C}$ for $10 \mathrm{~min}$. This was performed using the PTC-100 (Bio-Rad Laboratories, Inc., Hercules, CA, USA).

The PCR products were resolved on a $1 \%$ agarose gel electrophoresis (Shaanxi Pioneer Biotech Co., Ltd., Xi'an, China). The hTERT promoter (p) and CDX2 products were digested with HindIII/PstI and EcoRI/BamHI, respectively, and confirmed by DNA sequence analysis at Sangon Biotech Co. Ltd. (Shanghai, China).

Construction of lentiviral vectors. The hTERT promoter was first cloned into the pLenhanced green fluorescent protein (EGFP)-N1-5HRE-CEAp (27) plasmid (Translational Medical Center, First Affiliated Hospital of Xi'an Jiaotong University, Xi'an, China) at the HindIII and PstI sites by replacing CEAp with the restriction endoenzymes for $16 \mathrm{~h}$ at $37^{\circ} \mathrm{C}$, in order to derive a recombinant plasmid named pLEGFP-N1-5HRE-hTERTp. An incision enzyme and Taq DNA polymerase from Takara Bio, Inc. (Otsu, Japan) were used. Subsequently, the 5HRE-hTERTp fragment, which was digested with the restriction endoenzymes $B g I I I$ and Pst I in buffer at $37^{\circ} \mathrm{C}$ for $16 \mathrm{~h}$, was cloned into the lentiviral vector pLVX-EGFP-3FLAG (Translational Medical Center, First Affiliated Hospital of Xi'an Jiaotong University) by replacing the CMV promoter in the plasmid to generate the recombinant plasmid pLVX-5HRE-hTERTp-EGFP-3FLAG (designated as $5 \mathrm{Hh}$ ), into which the amplified CDX2 fragment was cloned by replacing EGFP to produce the recombinant plasmid pLVX-5HRE-hTERTp-CDX2-3FLAG (designated as 5HhC). The identity of the final recombinant lentiviral vector construct was confirmed by restriction endonuclease digestion and DNA sequence analysis at Sangon Biotech Co., Ltd.

Cell lines and cell cultures. Human epithelial kidney HEK 293T, human proximal tubular HK-2 and human CRC LoVo cells (Translational Medical center, First Affiliated Hospital of Xi'an Jiaotong University) were cultured in Dulbecco's modified Eagle's medium (DMEM) from Gibco Life Technologies (Carlsbad, CA, USA), supplemented with $10 \%$ fetal bovine serum obtained from GE Healthcare Life Sciences (Logan, UT, USA) in a humidified atmosphere with $5 \% \mathrm{CO}_{2}$ at $37^{\circ} \mathrm{C}$.

Generation and titration of lentiviruses. Recombinant lentiviruses were produced by co-transfecting 293T cells with the lentiviral expression plasmid $5 \mathrm{HhC}$ or the control plasmid $5 \mathrm{Hh}$, in addition to the $\mathrm{pCD} / \mathrm{NL}-\mathrm{BH} * \mathrm{DDD}$ and pLTR-G plasmids (Shanghai Sunbio Technology Co., Ltd., Shanghai, China) using Trans-EZ reagent (Shanghai Sunbio Technology Co., Ltd.). The $293 \mathrm{~T}$ cells $\left(6 \times 10^{5}\right)$ were cultured in a $10-\mathrm{cm}$ tissue culture plate with opti-MEM (Gibco Life Technologies). Transfection was performed when the cell density reached $30-40 \%$ confluence. Solution A was prepared by adding $0.5 \mathrm{ml}(0.5 \mathrm{mg} / \mathrm{ml}) 5 \mathrm{HhC}$ or $5 \mathrm{Hh}$ plasmid and $1 \mathrm{ml}$ $(0.2 \mathrm{mg} / \mathrm{ml}) \mathrm{pCD} / \mathrm{NL}-\mathrm{BH}$ *DDD or $0.5 \mathrm{ml}(0.2 \mathrm{mg} / \mathrm{ml}) \mathrm{pLTR}-\mathrm{G}$ plasmids (diluted with opti-MEM media) to $18 \mathrm{ml}$ opti-MEM media. Solution B was prepared by adding $0.5 \mathrm{ml}$ Trans-EZ to $18 \mathrm{ml}$ opti-MEM media. The transfection solution was prepared by adding solution B slowly to solution A. The mixture was agitated and then incubated at room temperature for $20 \mathrm{~min}$. The $293 \mathrm{~T}$ cells were plated in six-well plates prior to incubation with $3 \mathrm{ml}$ prepared transfection mixture in a humidified incubator with $5 \% \mathrm{CO}_{2}$ at $37^{\circ} \mathrm{C}$ for $30 \mathrm{~min}$. The culture media was then replaced with fresh DMEM. Infectious lentiviruses were harvested at $48 \mathrm{~h}$ post-transfection by collecting the medium and centrifuging at $500 \mathrm{x} \mathrm{g}$ and $4^{\circ} \mathrm{C}$ for $10 \mathrm{~min}$, then filtering the supernatant containing the lentiviruses through a $0.45 \mu \mathrm{m}$ polyvinylidene fluoride filter unit (EMD Millipore, Billerica, MA, USA) to concentrate it. The infectious titer was determined by quantitative PCR (qPCR). The total RNA of the transfected cells was extracted using TRIzol Reagent (Invitrogen Life Technologies,Carlsbad, CA, USA). Reverse transcription and PCR were performed using a Takara Bio, Inc. RNA PCR (AMV) kit with the CDX2 primers presented in Table I. The results were normalized against the level of the internal control. $\beta$-actin PCR amplifications were performed at $98^{\circ} \mathrm{C}$ for $2 \mathrm{~min}, 40$ cycles of $50^{\circ} \mathrm{C}$ for $2 \mathrm{~min}, 95^{\circ} \mathrm{C}$ for $10 \mathrm{~min}$ and $95^{\circ} \mathrm{C}$ for $15 \mathrm{sec}$, followed by an extension step at $60^{\circ} \mathrm{C}$ for 1 min (ABI PRISM 7000 Sequence Detection System). qPCR was performed in triplicate for each experiment, including for the non-template controls.

Infection of LoVo cells with lentiviruses. LoVo cells were cultured in six-well plates $\left(5 \times 10^{5}\right.$ cells/well $)$ overnight, infected with $5 \mathrm{HhC}$ or control $5 \mathrm{Hh}$ lentiviruses and exposed 
Table I. Primer sequences.

PCR product

Gene Primer $\quad$ Base sequence 5'-3'

(base pairs)

\begin{tabular}{llll}
\hline 5HRE & Forward & CGACGCGTATTATGCTAGTCCAC & 221 \\
hTERT & Forward & CCCAAGCTTCACAGACGCCCAGGACCGCGCTTC & 327 \\
& Reverse1 & AACTGCAGCCACGTGCGCCCACGTGCGCCCAC & \\
& Reverse2 & CCGCTCGAGCCACGTGCGCCCACGTGCGCCCAC & 943 \\
CDX2 & Forward & CGGAATTCATGTACGTGAGCTACCTCCTGGACAAGGAC & \\
& Reverse & CGGGATCCGTCTGGGTGACGGTGGGGTTTAGCACCCCCCAGTTG & \\
\hline
\end{tabular}

Underlined sections indicate the restriction sites. PCR, polymerase chain reaction.

to puromycin ( $800 \mu \mathrm{g} / \mathrm{ml}$; Gibco Life Technologies) for two weeks. The $5 \mathrm{HhC} / \mathrm{LoVo}$ or $5 \mathrm{Hh} / \mathrm{LoVo}$ cells were then routinely cloned (28).

Immunofluorescence assay. To detect CDX2 expression by the $5 \mathrm{HhC}$ lentivirus, the hTERT(+) LoVo and hTERT(-) HK-2 cells were infected with $5 \mathrm{HhC}$ lentiviruses in a humidified incubator with $5 \% \mathrm{CO}_{2}$ at $37^{\circ} \mathrm{C}$ for $48 \mathrm{~h}$ and the $\mathrm{CDX} 2$ expression was examined using an immunofluorescence assay. The 5HhC-infected LoVo and HK-2 cells were cultured and fixed with $4 \%$ paraformaldehyde (Shaanxi Pioneer Biotech Co., Ltd.) for $30 \mathrm{~min}$. The cells were stained with a primary monoclonal rabbit anti-FLAG antibody (1:200; F2555; Sigma-Aldrich, St. Louis, MO, USA) at $4^{\circ} \mathrm{C}$ overnight prior to incubation at $37^{\circ} \mathrm{C}$ for $30 \mathrm{~min}$ with a fluorescein isothiocyanate-conjugated goat anti-rabbit immunoglobulin (Ig) G secondary antibody (1:5,000; Wuhan Sanying Biotechnology, Wuhan, China). The cells were then mounted with DAPI solution (Santa Cruz Biotechnology, Inc., Dallas, TX, USA) and observed under a confocal fluorescence microscope (Leica DMi8; Leica Microsystems GmbH, Wetzlar, Germany) to evaluate FLAG expression.

MTT assay. The effects of $\mathrm{CoCl}_{2}$ on the viability of LoVo cells were detected using an MTT assay. The LoVo cells, at a density of $5 \times 10^{3} \mathrm{cells} /$ well, were cultured for $24 \mathrm{~h}$ and then treated with $100,200,300,400$ or $500 \mu \mathrm{mol} / 1 \mathrm{CoCl}_{2}$ (Sigma-Aldrich) for 1, 3, 5 or 7 days. The experiment was performed in triplicate. Subsequently, the plates were washed extensively with serum-free DMEM to remove $\mathrm{CoCl}_{2}$ and dead cells, and were exposed to $20 \mu \mathrm{l}(5 \mathrm{~g} / \mathrm{l}) \mathrm{MTT}$ (Sigma-Aldrich) for $4 \mathrm{~h}$. The resulting formazan crystals were dissolved in $200 \mu$ l dimethyl sulfoxide (Sigma-Aldrich) and the absorbance was measured at $490 \mathrm{~nm}$ with a microplate reader (Victor3; PerkinElmer, Inc., Waltham, MA, USA). The cytotoxicity of $\mathrm{CoCl}_{2}$ to $\mathrm{LoVo}$ cells was evaluated by determination of the survival rate of $\mathrm{LoVo}$ cells (calculated as A490 of treatment group/A490 of untreated group).

Western blot analysis. The $5 \mathrm{HhC} / \mathrm{LoVo}$ cells were cultured under a normoxic (absence of $\mathrm{CoCl}_{2}$ ) or hypoxic conditions (100, $200,300,400$ or $500 \mu \mathrm{mol} / 1 \mathrm{CoCl}_{2}$ ) for $24 \mathrm{~h}$ and then cultured for 12,24 or $36 \mathrm{~h}$ with the optimal concentration $(300 \mu \mathrm{mol} / \mathrm{l})$ of $\mathrm{CoCl}_{2}$. The relative ratios of recombinant CDX2 protein to control $\beta$-actin were determined by western blot analysis. Briefly, the $5 \mathrm{HhC}$ lentivirus-infected LoVo cells $\left(1 \times 10^{6}\right.$ cells) were lysed with $150 \mu$ lysis buffer ( $50 \mathrm{mM}$ Tris, $150 \mathrm{mM} \mathrm{NaCl}, 5 \mathrm{mMEDTA}$, 5 mM EGTA and 1\% SDS; pH 7.5; (Shaanxi Pioneer Biotech Co., Ltd.), followed by gentle sonication (Bio-Rad Laboratories, Inc.). Following quantification with Bradford reagent (Thermo Fisher Scientific, Waltham, MA, USA), the protein lysates ( $80 \mu \mathrm{g} / \mathrm{lane})$ of each sample were subjected to SDS-PAGE (Shaanxi Pioneer Biotech Co., Ltd.) with a machine from EMD Millipore on $10 \%$ gels and transferred to polyvinylidene fluoride membranes (EMD Millipore). Subsequent to being blocked with 5\% fat-free dry milk, the membranes were incubated with 1:1,000 diluted monoclonal rabbit anti-CDX2 (2475-1; Epitomics, Burlingame, CA, USA) and 1:3,000 diluted polyclonal rabbit anti- $\beta$-actin (BS10005; Bioworld Technology, Inc., St. Louis Park, MN, USA) at $4^{\circ} \mathrm{C}$, overnight prior to incubation with horseradish peroxidase-conjugated goat anti-rabbit $\operatorname{IgG}$ secondary antibody (OriGene Technologies, Inc., Beijing, China) for $30 \mathrm{~min}$ at $37^{\circ} \mathrm{C}$, followed by visualization with enhanced chemiluminescence (Amresco LLC, Solon, OH, USA).

Reverse transcription (RT)-PCR analysis. The $5 \mathrm{HhC} / \mathrm{LoVo}$ cells were cultured under normoxic or hypoxic conditions and the transcription of recombinant CDX2 mRNA was determined by RT-PCR using the primers listed in Table I. In brief, total RNA was extracted from the infected cells cultured under normoxia or hypoxia using TRIzol (Gibco Life Technologies, Grand Island, NY, USA), according to the manufacturer's instructions. The resulting RNAs were treated with RNase-free DNase (Promega Corp., Madison, WI, USA) and reverse transcribed into cDNA using an RT-PCR kit (Invitrogen Life Technologies) according to the manufacturer's instructions. PCR amplifications were performed in duplicate at $98^{\circ} \mathrm{C}$ for $2 \mathrm{~min}$ and subjected to 35 cycles of $98^{\circ} \mathrm{C}$ for $20 \mathrm{sec}, 59^{\circ} \mathrm{C}$ for $30 \mathrm{sec}$ and $72^{\circ} \mathrm{C}$ for $1 \mathrm{~min}$, followed by an extension at $72^{\circ} \mathrm{C}$ for $10 \mathrm{~min}$. The PCR products were resolved by agarose gel electrophoresis using a ChemiDoc System (ChemiDoc ${ }^{\mathrm{TM}}$ MP System 170-8280; Bio-Rad Laboratories, Inc.).

Cloning assay. A total of $2005 \mathrm{HhC} / \mathrm{LoVo}$ and $2005 \mathrm{Hh}$ cells plated on $60-\mathrm{mm}$ cell culture dishes were cultured in a humidified incubator with $5 \% \mathrm{CO}_{2}$ at $37^{\circ} \mathrm{C}$ for three weeks. The cloning cells were fixed with methanol (Shaanxi Pioneer Biotech Co., Ltd.) at room temperature for $15 \mathrm{~min}$ and then stained by 

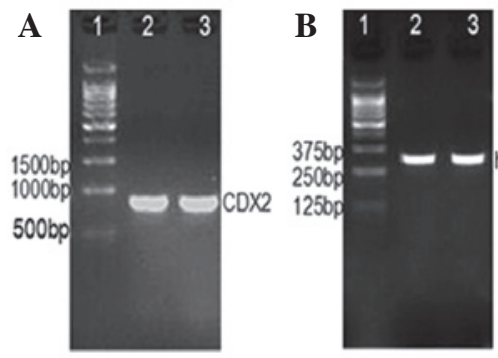

$\mathbf{E}$

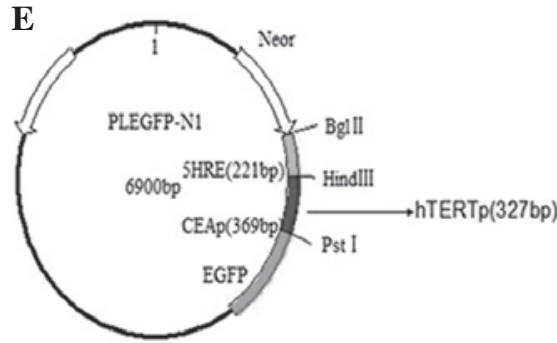

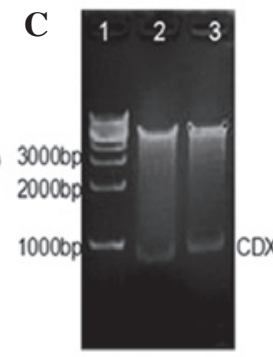

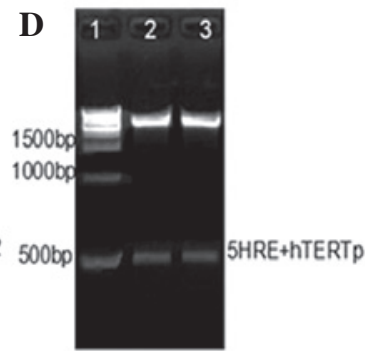

$\mathbf{F}$

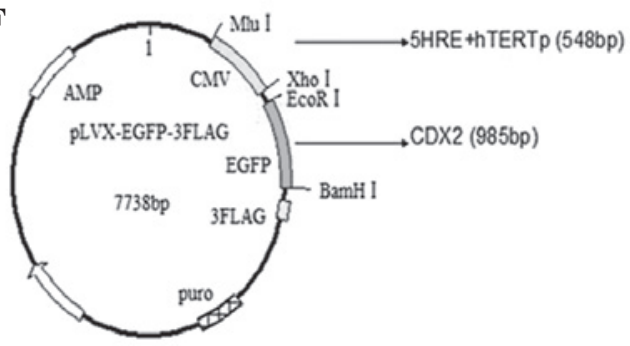

Figure 1. Characterization of recombinant plasmids. (A) Electrophoretogram of CDX2 PCR products. (B) Electrophoretogram of hTERTp PCR products. (C) Restriction endonuclease enzyme digestions of pLVX-5HRE-hTERTp-CDX2-3FLAG DNA. (D) Restriction endonuclease enzyme digestions of pLEGFP-N1-5HRE-hTERTp DNA. Lanes: 1, DNA marker; 2 and 3, PCR or enzyme-digested products. (E) Schematic chart of the recombinant plasmid pLEGFP-N1-5HRE-hTERTp. (F) Schematic chart of the recombinant plasmid pLVX-5HRE-hTERTp-CDX2-3FLAG. CDX2, caudal-related homeobox; PCR, polymerase chain reaction; hTERTp, human telomerase reverse transcriptase promoter; bp, base pairs.

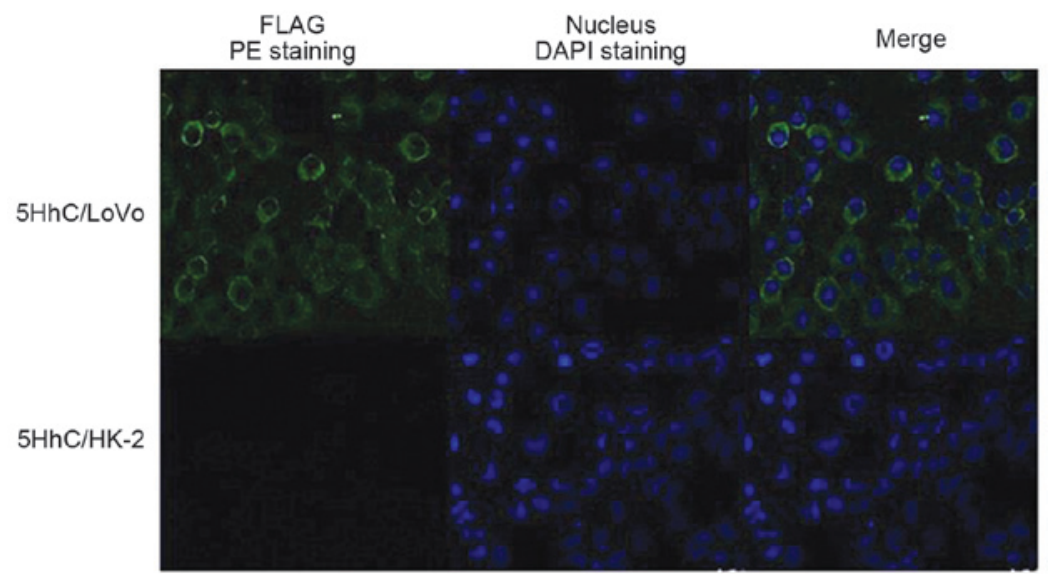

Figure 2. 5HhC-infected LoVo cells, but not HK-2 cells, are positive for immunofluorescent FLAG staining. The 5HhC-infected LoVo and HK-2 cells were fixed with $4 \%$ paraformaldehyde for $30 \mathrm{~min}$ and stained with monoclonal rabbit anti-FLAG antibody and fluorescein isothiocyanate-goat anti-rabbit immunoglobulin G, mounted with DAPI solution and observed under a fluorescence microscope. Data presented are representative images (magnification, x100) from two separate experiments. 5HhC, pLVX-5HRE-hTERTp-CDX2-3FLAG; PE, plasmalemma.

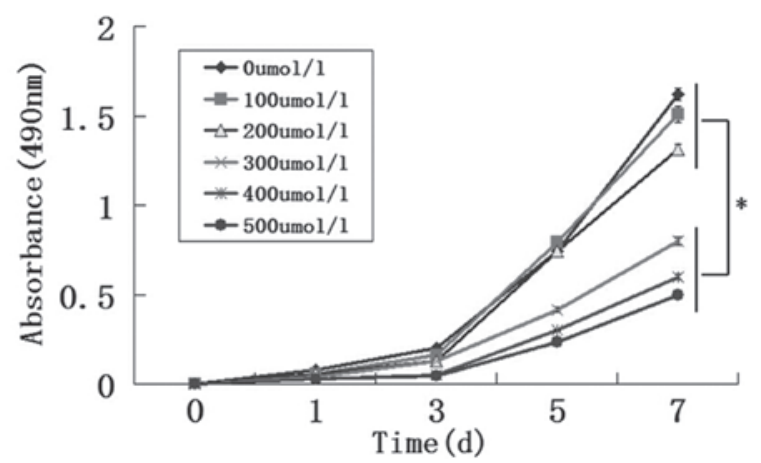

Figure 3. High concentrations of $\mathrm{CoCl}_{2}$ inhibit the proliferation of LoVo cells in vitro, determined by MTT assay. LoVo cells were treated with various concentrations of $\mathrm{CoCl}_{2}(100-500 \mu \mathrm{mol} / \mathrm{l})$ for seven days. A total of six samples were analyzed in each group. The assay was repeated independently a minimum of three times. Survival rate $(\%)=1$-treatment group A490 nm/untreated group $\mathrm{A} 490 \mathrm{~nm}$. Values are presented as the mean \pm standard deviation; ${ }^{*} \mathrm{P}<0.05$.
Giemsa solution. The clones containing $\geq 50$ cells [counted using a Leica M125 microscope (Leica Microsystems GmbH, Heidelberg, Germany)] were regarded as true clones (29).

Statistical analysis. All experiments were repeated three times. The data from all experiments was pooled, and the results were expressed as the mean \pm standard deviation. Differences in mean values were analyzed by one-way analysis of variance followed by Student's t-test with SPSS software version 13.0 (SPSS, Inc., Chicago, IL, USA). P $<0.05$ was considered to indicate a statistically significant difference.

\section{Results}

Recombinant plasmids were successfully generated. The 327 base pairs (bp) hTERTp and 985 bp 

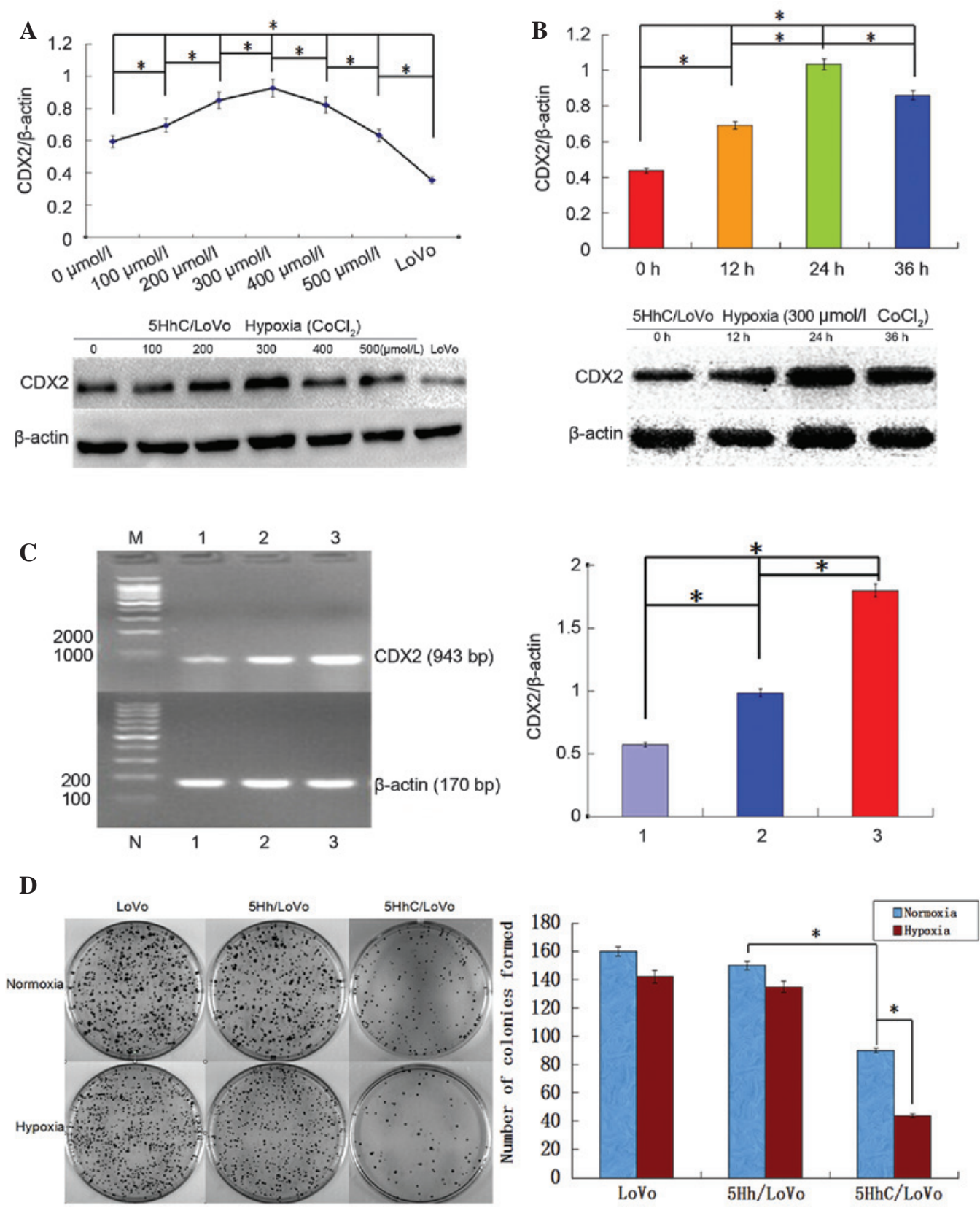

Figure 4. Expression levels of CDX2 in 5HhC LoVo cells and the effect of CDX2 overexpression on LoVo cell proliferation. (A) Western blot analysis of $\mathrm{CDX} 2$ expression. The 5HhC/LoVo cells and LoVo cells were cultured under normoxic or hypoxic conditions (100-500 $\mu$ mol/ $\left./ \mathrm{CoCl} \mathrm{C}_{2}\right)$ for $24 \mathrm{~h}$. (B) Western blot analysis of CDX2 expression. The $5 \mathrm{HhC} / \mathrm{LoV}$ o cells were cultured under hypoxic conditions $\left(300 \mu \mathrm{mol} / 1 \mathrm{CoCl}_{2}\right)$ for $0,12,24$ or $36 \mathrm{~h}$. (C) Reverse transcription-polymerase chain reaction analysis of CDX2 mRNA expression. The 5HhC/LoVo cells were cultured under a normoxic or hypoxic conditions $\left(300 \mu \mathrm{mol} / 1 \mathrm{CoCl}_{2}\right)$ for $24 \mathrm{~h}$. M, DNA marker; 1 , LoVo cells; $2,5 \mathrm{HhC} / \mathrm{LoVo}$ cells under normoxic conditions; 3 , 5HhC/LoVo cells under hypoxic conditions. (D) Clone formation of $\mathrm{LoVo}, 5 \mathrm{Hh} / \mathrm{LoVo}$ or $5 \mathrm{HhC} / \mathrm{LoV}$ o cells. Each group had a hypoxic control $\left(200 \mu \mathrm{mol} / 1 \mathrm{CoCl}{ }_{2}\right.$; red bars). All data presented are representative images of each group of cells from three separate experiments. The results are presented as the mean \pm standard deviation ("P<0.05). CDX2, caudal-related homeobox; 5HhC, pLVX-5HRE-hTERTp-CDX2-3FLAG; 5Hh, pLVX-5HRE-hTERTp-EGFP-3FLAG; bp, base pairs.

CDX2 DNA fragments were successfully amplified by PCR (Fig. 1A and B). The restricted enzyme digestions (Fig. 1C and D) and sequencing demonstrated that the recombinant plasmids pLEGFP-N1-5HRE-hTERTp and pLVX-5HRE-hTERTp-CDX2-3FLAG (Fig. 1E and F) were also successfully constructed.

5HhC-infected LoVo cells, but not HK-2 cells, express FLAG in vitro. An immunofluorescence assay was conducted to examine FLAG expression of 5HhC in the hTERT(+) LoVo and hTERT(-) HK-2 cell lines. It was observed that FLAG was expressed on the membrane and cytoplasm of 5HhC-infected LoVo cells, but not 5HhC-infected HK-2 cells (Fig. 2). This indicated that hTERT specifically directed exogenous gene expression in hTERT(+), but not hTERT(-) cell lines.

High concentrations of $\mathrm{CoCl}_{2}$ attenuate LoVo cell proliferation in vitro. The cytotoxic effect of $\mathrm{CoCl}_{2}$ on $\mathrm{LoVo}$ cells was investigated using an MTT assay. The results demonstrated that cell viability was not influenced by $\mathrm{CoCl}_{2}$ at 100 or 
$200 \mu \mathrm{mol} / \mathrm{l}(\mathrm{P}>0.05)$, but the cell viability was suppressed with $300-500 \mu \mathrm{mol} / 1 \mathrm{CoCl}_{2}(\mathrm{P}<0.05)$, particularly at day 7 (Fig. 3).

High CDX2 expression levels with $5 H$ hC are induced in the hTERT(+) cell line under hypoxic conditions. The levels of recombinant $\mathrm{CDX} 2$ protein relative to control $\beta$-actin expression following $\mathrm{CoCl}_{2}$ hypoxic treatment over time was compared between $5 \mathrm{HhC} / \mathrm{LoVo}$ and LoVo cells. Following $24 \mathrm{~h}$ of hypoxic treatment, the relative expression levels of $\mathrm{CDX} 2$ were upregulated at $\mathrm{CoCl}_{2}$ concentrations from $100-500 \mu \mathrm{mol} / 1 \quad(\mathrm{P}<0.05)$, with the greatest effect on CDX2 expression observed following treatment with $300 \mu \mathrm{mol} / 1$ $\mathrm{CoCl}_{2}$, compared with that of $5 \mathrm{HhC} / \mathrm{LoV}$ o cells without $\mathrm{CoCl}_{2}$ treatment $(\mathrm{P}<0.05$; Fig. $4 \mathrm{~A})$. In $5 \mathrm{HhC} / \mathrm{LoVo}$ cells treated with $300 \mu \mathrm{mol} / 1 \mathrm{CoCl}_{2}$, the highest CDX2 expression levels were observed following $24 \mathrm{~h}$ of treatment when compared with those at 0,12 or $36 \mathrm{~h}(\mathrm{P}<0.05$; Fig. 4B). Subsequently, $5 \mathrm{HhC} / \mathrm{LoV}$ cells were treated for $24 \mathrm{~h}$ under normoxic or hypoxic conditions (with $300 \mu \mathrm{mol} / 1 \mathrm{CoCl}_{2}$ ). The relative expression levels of CDX2 mRNA in $5 \mathrm{HhC} / \mathrm{LoV}$ cells under hypoxic conditions were observed to be significantly higher when compared with those under normoxic conditions $(\mathrm{P}<0.05$; Fig. $4 \mathrm{C})$. The data presented indicated that the CDX2 mRNA and protein expression levels were upregulated in $5 \mathrm{HhC} / \mathrm{LoVo}$ cells, particularly under hypoxic conditions.

To further assess the potential effects of CDX2 expression with $5 \mathrm{HhC}$ on the proliferation of LoVo cells, a cloning assay was conducted with $5 \mathrm{HhC} / \mathrm{LoVo}$ and LoVo cells. The proliferation results demonstrated that the clone numbers and size in $5 \mathrm{HhC} / \mathrm{LoV}$ o cells were significantly reduced compared with those of LoVo cells $(\mathrm{P}<0.05)$. Notably, the proliferation levels of $5 \mathrm{HhC} / \mathrm{LoV}$ cells under hypoxic conditions were significantly lower compared with those under normoxic conditions $(\mathrm{P}<0.05$; Fig. 4D). These results indicated that a hypoxic environment resulted in upregulation of CDX2 expression with $5 \mathrm{HhC}$ to inhibit LoVo cell proliferation via the $5 \mathrm{HRE}$ enhancers.

\section{Discussion}

In the present study, a recombinant lentivirus with enhanced CDX2 expression driven by hTERTp and 5 HRE enhancers was generated, and it was observed that CDX2 was highly expressed in hTERT positive cells under hypoxic conditions, which attenuated CRC cell proliferation in vitro.

It was identified that CDX2 expression was detected in hTERT(+) LoVo cells, but not in hTERT(-) HK-2 cells, suggesting that the $5 \mathrm{HhC}$ vector was hTERT-specific in vitro. The hTERT promoter, which is active in the majority of cancer cell lines but not in normal cells, has been previously reported as a useful tool for tumor transcriptional targeting (30-32). In addition, it has been demonstrated to effectively target A549 human lung adenocarcinoma cells and MKN45 human gastric cancer cells (16).

In order to enhance CDX2 expression under the hTERT promoter, five copies of HRE were positioned upstream of the hTERT promoter. It was observed that $5 \mathrm{HhC} / \mathrm{LoVo}$ cells under hypoxic conditions, produced by treatment with $300 \mu \mathrm{mol} / 1 \mathrm{CoCl}_{2}$ for $24 \mathrm{~h}$, exhibited the greatest expression levels of CDX2 compared with those under normoxic conditions without $\mathrm{CoCl}_{2}$. A previous study reported that the development of CRC was dependent on the tumor microenvironment (33). The observations of the current study were in agreement with a previous study, in which five copies of HRE under the control of a CMV promoter induced bacterial cytosine deaminase expression in the bacterial cytosine deaminase/5-fluorocytosine gene therapy system under hypoxic conditions, enhancing the efficacy of radiotherapy in a tumor xenograft (34). In the present study, it was observed that $5 \mathrm{HhC} / \mathrm{LoV}$ o cells under hypoxic conditions exhibited significantly inhibited LoVo cell proliferation compared with those under normoxic conditions, suggesting that CDX2 expression was induced under hypoxic conditions to suppress CRC cell proliferation. This is consistent with the role of CDX2 as a tumor-suppressor gene in colorectal cancer (35). A non-transcriptional function of CDX2 is that it suppresses tumorigenesis via p27Kip1 stabilization, and low levels of CDX2 have been reported to accelerate colon tumorigenesis by reducing p27Kip1 levels (36). Notably, mutation of a subdomain in the N-terminus of CDX2 has been reported to abrogate the anti-proliferative effects of CDX2, which may be via inhibition of $\beta$-catenin/T-cell factor (TCF) transcriptional activity by disrupting the $\beta$-catenin-TCF protein complex in colon cancer cells (37). CDX2 tumor suppression may also function via the extracellular signal-regulated kinase $1 / 2$ pathway in CRC (38). Clinically, a reduction in CDX2 expression is correlated with poor overall survival amongst patients with colorectal cancer (39).

In conclusion, a recombinant lentivirus with the hTERT promoter and five HREs promoted expression of the tumor suppressor CDX2 in CRC cells under hypoxic conditions, and was effective at targeting CRC cells in vitro. CDX2 expression under the hTERT promoter and five HREs may provide a potential tool for the treatment and gene therapy of CRC.

\section{Acknowledgements}

The current study was supported by grants from the National Natural Science Foundation of China (grant nos. 81101874, 81172362 and 81172359), the Science and Technology Project of Shaanxi Province (grant no. 2011-K12-19), the Science and Technology Plan and Integrated Innovation Engineering Project of Shaanxi Province (grant no. 2013KTCQ03-08) and the Clinical Innovation Fund of the First Affiliated Hospital of Xi'an Jiaotong University (grant nos. 12ZD12 and 12ZD21).

\section{References}

1. László L: Predictive and prognostic factors in the complex treatment of patients with colorectal cancer. Magy Onkol 54: 383-394, 2010.

2. Akkad J, Bochum S and Martens UM: Personalized treatment for colorectal cancer: novel developments and putative therapeutic strategies. Langenbecks Arch Surg 400: 129-143, 2015.

3. O'Connor JP, Rose CJ, Jackson A, et al: DCE-MRI biomarkers of tumour heterogeneity predict CRC liver metastasis shrinkage following bevacizumab and FOLFOX-6. Br J Cancer 105: 139-145, 2011.

4. Akhavan-Niaki H and Samadani AA: Molecular insight in gastric cancer induction: an overview of cancer stemness genes. Cell Biochem Biophys 68: 463-473, 2014

5. Natoli M, Christensen J, El-Gebali S, Felsani A and Anderle P: The role of CDX2 in Caco-2 cell differentiation. Eur J Pharm Biopharm 85: 20-25, 2013. 
6. Lin ME, Huang D, Deng BH, Lv YS, Rong L and Yao YS Expression and functional role of $\mathrm{Cdx} 2$ in intestinal metaplasia of cystitis glandularis. J Urol 190: 1083-1089, 2013.

7. Zheng J, Sun X, Wang W and Lu S: Hypoxia-inducible factor-1alpha modulates the down-regulation of the homeodomain protein CDX2 in colorectal cancer. Oncol Rep 24: 97-104, 2010

8. Aoki K, Tamai Y,Horiike S, Oshima M and Taketo MM: Colonic polyposis caused by mTOR-mediated chromosomal instability in Apc+/Delta716 Cdx2+/- compound mutant mice. Nat Genet 35: 323-330, 2003

9. Chawengsaksophak K, James R, Hammond VE, Köntgen F and Beck F: Homeosis and intestinal tumours in $\mathrm{Cdx} 2$ mutant mice. Nature 386: 84-87, 1997

10. Olsen AK, Coskun M, Bzorek M, Kristensen MH, Danielsen ET, Jørgensen S, Olsen J, Engel U, Holck S and Troelsen JT: Regulation of APC and AXIN2 expression by intestinal tumor suppressor CDX2 in colon cancer cells. Carcinogenesis 34: 1361-1369, 2013

11. Gross I, Duluc I, Benameur T, Calon A, Martin E, Brabletz T, Kedinger $M$, Domon-Dell $C$ and Freund JN: The intestine-specific homeobox gene $\mathrm{Cdx} 2$ decreases mobility and antagonizes dissemination of colon cancer cells. Oncogene 27: 107-115, 2008

12. Hong KD, Lee D, Lee Y, Lee SI and Moon HY: Reduced CDX2 expression predicts poor overall survival in patients with colorectal cancer. Am Surg 79: 353-360, 2013.

13. Zheng JB, Sun XJ, Qi J, Li SS, Wang W, Ren HL, Tian Y, Lu SY and Du JK. Effects of homeodomain protein CDX2 expression on the proliferation and migration of lovo colon cancer cells Pathol Oncol Res 17:743-751, 2011.

14. Xie Y, Li L, Wang X, Qin Y, Qian Q, Yuan X and Xiao Q: Overexpression of $\mathrm{Cdx} 2$ inhibits progression of gastric cancer in vitro. Int J Oncol 36: 509-516, 2010.

15. Wang W, Jin B, Li W, Xu CX, Cui FA, Liu B, Yan YF, Liu XX and Wang XL. Targeted antitumor effect induced by hTERT promoter mediated ODC antisense adenovirus. Mol Biol Rep 37: 3239-3247, 2010

16. Bougel S, Renaud S, Braunschweig R, Loukinov D, Morse HC III, Bosman FT, Lobanenkov V and Benhattar J: PAX5 activates the transcription of the human telomerase reverse transcriptase gene in B cells. J Pathol 220: 87-96, 2010.

17. Zhang P, Tan J, Yang DB, et al: Gene therapy using the human telomerase catalytic subunit gene promoter enables targeting of the therapeutic effects of vesicular stomatitis virus matrix protein against human lung adenocarcinoma. Exp Ther Med 4: 859-864, 2012

18. Hioki M, Kagawa S, Fujiwara T, Sakai R, Kojima T, Watanabe Y, Hashimoto Y, Uno F, Tanaka N and Fujiwara T: Combination of oncolytic adenovirotherapy and Bax gene therapy in human cancer xenografted models. Potential merits and hurdles for combination therapy. Int J Cancer 122: 2628-2633, 2008.

19. Gout S and Huot J: Role of cancer microenvironment in metastasis: focus on colon cancer. Cancer Microenviron 1: 69-83, 2008.

20. Jubb AM, Buffa FM and Harris AL: Assessment of tumour hypoxia for prediction of response to therapy and cancer prognosis. J Cell Mol Med 14: 18-29, 2010.

21. Law AY, Ching LY, Lai KP and Wong CK: Identification and characterization of the hypoxia-responsive element in human stanniocalcin-1 gene. Mol Cell Endocrinol 314: 118-127, 2010.

22. Zhang J, Shi Q, Chen X, et al: Hypoxia-regulated neurotrophin-3 expression by multicopy hypoxia response elements reduces apoptosis in PC12 cells. Int J Mol Med 30: 1173-1179, 2012.
23. Hu J, Stiehl DP, Setzer C, Wichmann D, Shinde DA, Rehrauer H, Hradecky P, Gassmann M and Gorr TA: Interaction of HIF and USF signaling pathways in human genes flanked by hypoxia-response elements and E-box palindromes. Mol Cancer Res 9: 1520-1536, 2011.

24. Tian Y, Sun XJ, Wang W and Wang W: TSST-1 regulated synergistically by 5HRE and CEAp activates lymphocytes to kill CEA-positive tumor cells specifically. Xi Bao Yu Fen Zi Mian Yi Xue Za Zhi 26: 525-529, 2010 (In Chinese).

25. Sun XJ, Lu L, Lu SY, Zhou PH and Wang W: The construction of 5HRE inducible TSST-1 gene therapy vector targeting for CEA-positive tumors. Chin J Cell Mol Immunol 25: 863-865, 2009.

26. Ren HL, Sun XJ, Zheng JB, Wang Z, Wang W and Cheng L: Over-expression CDX2 inhibits growth of colorectal transplanted tumors in mude mice. Chin J Cancer Biotherapy 18: 434-436, 2011

27. Wang W, Sun X, Lu L, Zheng JB, Tian Y and Wang W: Cytotoxicity of lymphocytes activated by superantigen toxic-shock-syndrome toxin-1 against colorectal cancer LoVo cells. Mol Cell Biochem 376: 1-9, 2013.

28. Li X, Wang K, Ren Y, et al: MAPK signaling mediates sinomenine hydrochloride-induced human breast cancer cell death via both reactive oxygen species-dependent and -independent pathways: an in vitro and in vivo study. Cell Death Dis 5: e1356 2014

29. Ji J and Zheng PS: Expression of Sox 2 in human cervical carcinogenesis. Hum Pathol 41: 1438-1447, 2010.

30. Xu Y, Hou J, Liu Z, Yu H, Sun W, Xiong J, Liao Z, Zhou F, $\mathrm{Xie} \mathrm{C}$ and Zhou Y: Gene therapy with tumor-specific promoter mediated suicide gene plus IL-12 gene enhanced tumor inhibition and prolonged host survival in a murine model of Lewis lung carcinoma. J Transl Med 9: 39, 2011.

31. Zhang H, Liao ZK, Sun WJ, Huang C, Xiong J, Zhou FX, Xie CH and Zhou YF: Enhanced suicide gene therapy using a tumor-specific promoter in combination with cisplatin. Mol Med Rep 2: 1017-1022, 2009

32. Nemunaitis J, Tong AW, Nemunaitis M, et al: A phase I study of telomerase-specific replication competent oncolytic adenovirus (telomelysin) for various solid tumors. Mol Ther 18: 429-434, 2010.

33. Taketo MM: Roles of stromal microenvironment in colon cancer progression. J Biochem 151: 477-481, 2012.

34. Liu J, Harada H, Ogura M, Shibata T and Hiraoka M: Adenovirus-mediated hypoxia-targeting cytosine deaminase gene therapy enhances radiotherapy in tumour xenografts. $\mathrm{Br}$ J Cancer 96: 1871-1878, 2007.

35. Hryniuk A, Grainger S, Savory JG and Lohnes D: Cdx1 and $\mathrm{Cdx} 2$ function as tumor suppressors. J Biol Chem 289: 33343-33354, 2014.

36. Aoki K, Kakizaki F, Sakashita H, Manabe T, Aoki M and Taketo MM: Suppression of colonic polyposis by homeoprotein CDX2 through its nontranscriptional function that stabilizes p27Kip1. Cancer Res 71: 593-602, 2011.

37. Guo RJ, Funakoshi S, Lee HH, Kong J and Lynch JP: The intestine-specific transcription factor $\mathrm{Cdx} 2$ inhibits beta-catenin/TCF transcriptional activity by disrupting the beta-catenin-TCF protein complex. Carcinogenesis 31: $159-166,2010$

38. Krueger F, Madeja Z, Hemberger M, McMahon M, Cook SJ and Gaunt SJ: Down-regulation of $\mathrm{Cdx} 2$ in colorectal carcinoma cells by the Raf-MEK-ERK 1/2 pathway. Cell Signal 21: 1846-1856, 2009.

39. Olsen J, Espersen ML, Jess P, Kirkeby LT and Troelsen JT: The clinical perspectives of CDX2 expression in colorectal cancer: a qualitative systematic review. Surg Oncol 23: 167-176, 2014. 